\title{
A consulta em Medicina Geral e Familiar
}

José Augusto Simões*

"A unidade essencial da prática médica é a ocasião em que, na intimidade de um consultório ou do quarto de um doente, uma pessoa que está doente ou acredita que o está, procura o conselho de um médico em quem confia. Isto é uma consulta e tudo o resto na prática da medicina deriva dela. O propósito da consulta é que o médico, tendo recolhido os indícios, dará uma explicação e um conselho». ${ }^{1}$

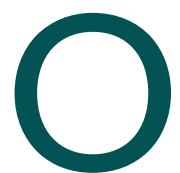
processo de consulta acontece no contexto de um relacionamento entre o médico e o paciente. A construção deste relacionamento depende da empatia, um elemento emocional, e da comunicação, um elemento intelectal. Ambos são, claro, trocas bilaterais. ${ }^{2}$

Mas a consulta é um procedimento diagnóstico e terapêutico de elevada complexidade técnica e o seu êxito depende muito da qualidade da relação médico-paciente nela desenvolvida. ${ }^{3}$

Por outro lado, se na relação médico-tecnologia, a competência está no saber fazer e saber quando fazer; na relação médico-paciente, para além desta competência, é necessário saber como ser e saber quando o ser. Estas duas competências têm de ser constantes ao longo de todas as fases da consulta. No entanto, a observação da prática mostra que se na fase de abertura existe alguma diminuição no grau de empenho do clínico, tal repercute-se nas fases subsequentes da consulta $e$ condiciona o resultado final. ${ }^{3}$

A atmosfera de uma sala de espera de um consultório ou de uma unidade de saúde pode transmitir um acolhimento amável e eficiente, ou o oposto. $\mathrm{O}$ secretariado clínico pode pôr o paciente à vontade, ou o contrário. Estas primeiras impressões transmitem ao paciente algo importante sobre o médico e a sua equipa. ${ }^{2}$

O modo como o médico saúda o paciente também

* Médico de Família na Unidade de Saúde Familiar (USF) Marquês de Marialva, Agrupamento de Centros de Saúde (ACES) do Baixo Mondego III Professor adjunto da Escola Superior de Saúde da Universidade de Aveiro (ESSUA) Editor da Revista Portuguesa de Clínica Geral (RPCG) tem uma importância imensurável face ao tempo que demora. Levanta-se, sorri e aperta a mão, ou continua a escrever notas sobre o último paciente ou atende o telefone. O sentir um bom acolhimento, um interesse por si, como uma pessoa distinta da anterior e da seguinte, a disponibilidade em ouvir qualquer problema, são factos que podem determinar em grande parte o sucesso ou o falhanço da consulta. ${ }^{2-5}$

A empatia pode crescer com os outros passos da consulta, qualquer que seja o cenário médico, e quer o contacto seja de apenas uma consulta ou de um relacionamento contínuo. Mas a empatia não depende apenas do médico, havendo a registar que alguns pacientes chegam mesmo a ser hostis, parecendo mesmo incapazes de construir um relacionamento quer com um médico em particular, quer com qualquer outra pessoa, o que irá requerer uma maior atenção e disponibilidade por parte do médico., ${ }^{2,4}$

É muito difícil fazer uma consulta satisfatória se o médico e o paciente não falarem a mesma língua, e esta situação, mesmo em sentido literal, não é rara. No entanto, é mais comum quando o paciente não compreende a linguagem do médico. É muito importante que o clínico descubra o que o paciente pensa, receia e compreende sobre a sua situação, e se certifique, antes do fim da consulta, que ele compreendeu aquilo que lhe disse, quer sobre o problema, quer sobre o prognóstico e o tratamento. Isto leva tempo, mas é um tempo bem gasto. ${ }^{2-5}$

O médico de família pode ser consultado por pacientes de qualquer idade, de ambos os sexos, e com qualquer ocupação. O leque de problemas que lhe trazem é muito lato, pelo que o seu trabalho se centra na pessoa e não em problemas de um tipo particular. Por vezes centra-se mesmo na família. Os seus cuidados são contínuos, pelo que o contacto com o paciente se alonga frequentemente, por vários anos, o que leva a que a consulta em medicina geral e familiar não seja um acontecimento único, mas antes um processo que se realiza ao longo de um certo período de tempo. Além 
disso, dois ou mais membros da mesma família podem ir à consulta, devido a um problema comum. ${ }^{2}$

Para que a consulta seja um meio adequado na relação médico-paciente numa perspectiva global, é preciso que os clínicos estejam conscientes dos factores essenciais da comunicação frente a frente, assim como das diferentes modalidades de comunicação na consulta, que constituem a mensagem do paciente para o médico e a resposta deste. Por outro lado, também é importante que saibam que, para que a consulta seja um veículo adequado de transmissão de informações e de educação para a saúde, é ainda necessário que os médicos dominem e executem técnicas de administração de instruções e de conselhos aos seus pacientes., ${ }^{4,6-8}$

Um médico é avaliado pelos seus registos e pela forma como os utiliza. O compromisso de fazer um diagnóstico escrito, mesmo que provisório, é uma obrigação ética que todos os médicos devem manter. O registo clínico é uma ferramenta essencial na prática do médico de família. É um suporte informativo e meio de comunicação, reflecte a qualidade dos cuidados médicos, contribui para a formação e para a investigação. Em medicina geral e familiar, a necessidade de organizar os dados provenientes de cuidados prestados de forma contínua, e por longos períodos, relança o tema e leva a reanalisar a actualidade e pertinência da utilização da metodologia SOAP, e a sua adaptabilidade face às novas aplicações informáticas., ${ }^{2,9}$

A sociedade actual procura avaliar a prestação dos serviços que utiliza. Contudo, a informação disponível é virtualmente inútil se não houver meios de a ordenar, pesar e digerir. Os indicadores de desempenho, ao avaliarem elementos mensuráveis da prática clínica diária, permitem o estabelecimento de prioridades e de decisões políticas de gestão e avaliação das mudanças nos sistemas de saúde.,10

Sendo o tema deste dossier a consulta, deseja-se que tudo o que nele se publica venha a ser conteúdo de ensino/aprendizagem na formação do médico de família, e possa, em qualquer altura da sua vida, ser-lhe útil, particularmente quando ele e o paciente se encontrarem no consultório ou no domicílio, isto é, naqueles momentos que Juan Gérvas e colaboradores consideram sagrados. ${ }^{11}$

\section{REFERÊNCIAS BIBLIOGRÁFICAS}

1. Spence J. The Purpose and Practice of Medicine. London: Oxford University Press; 1960.

2. Horder J, et al. O Clínico Geral do Futuro. $2^{\text {a }}$ edição. Porto: Departamento de Clínica Geral da Faculdade de Medicina do Porto; 1993.

3. Nunes JM. A abertura da Consulta. O fim está no princípio. Rev Port Clin Geral 2009 Mar-Abr; 25 (3): 199-206.

4. Nunes JM. Comunicação em Contexto Clínico. Lisboa: Bayer HealthCare; 2007.

5. Ramos V. A consulta em 7 passos. Rev Port Clin Geral 2009 Mar-Abr; 25 (3): 208-20.

6. Hespanhol AP, Couto L, Martins C, Viana M. Educação para a Saúde e Prevenção na Consulta de Medicina Geral e Familiar - I. Rev Port Clin Geral 2009 Mar-Abr; 25 (3): 236-41.

7. Hespanhol AP, Couto L, Martins C, Viana M. Educação para a Saúde e Prevenção na Consulta de Medicina Geral e Familiar - II. Rev Port Clin Geral 2009 Mar-Abr; 25 (3): 242-52.

8. Pendleton D, SchofieldT, Tate P, Havelock P.A Consulta: Uma Abordagem à Aprendizagem e Ensino. Porto: Departamento de Clínica Geral da Faculdade de Medicina do Porto; 1993.

9. Queiroz MJ. SOAP Revisitado. Rev Port Clin Geral 2009 Mar-Abr; 25 (3): 221-6.

10. Santos I, Ribeiro IL. Indicadores de desempenho na consulta. Rev Port Clin Geral 2009 Mar-Abr; 25 (3): 227-35.

11. Gérvas J, Pérez Fernández M, Gutiérrez Parres B. Consultas sagradas: serenidade en el apresuramiento. Aten Primaria 2009 Jan; 41(1):41-4.

\section{ENDEREÇO PARA CORRESPONDÊNCIA}

José Augusto Simões

Rua Teófilo braga, 25 - 5DTO

3030-076 Coimbra

E-mail: jars@apmcg.pt 